DOI 10.31718/2077-1096.20.1.126

УДК 616.832-004.2

\title{
Шульга 0.Д.
}

\section{ПРОГНОЗ ПЕРЕБІГУ РОЗСІЯНОГО СКЛЕРОЗУ: РЕЗУЛЬТАТИ ПРОСПЕКТИВНОГО ДОСЛІДЖЕННЯ}

КЗ «Волинська обласна клінічна лікарня», м. Луцьк

Актуальність. Перебіг розсіяного склерозу мінливий та непередбачуваний. Незважаючи на значні зусилля і дослідження протягом десятиліть, досі однією з основних проблем і питань як для неврологів, так і для хворих, залишається визначення прогнозу перебігу розсіяного склерозу, фракторів та маркерів прогресії, що впливають на нього. Проспективні дослідження зможуть частково надати оцінку фракторів, що визначають прогноз перебігу РС. Мета: оцінити фактори що впливають на перебіг розсіяного склерозу за даними 5-річного динамічного спостереження. Матеріали і методи. Було обстежено 175 хворих з розсіяним склерозом в динаміці протягом 5 річного періоду спостереження. Застосовували клінічні та параклінічні методи обстеження. Статистичний аналіз здійснено за допомогою програми Microsoft Excel for Windows ma SPSS. B роботі використані стандартні описові статистики. Для аналізу категоріальних використано хі-квадрат Пірсона. Оцінка величини та спрямованості кореляційної залежності проводилась за допомогою коефріцієнту непараметричної кореляції Спірмена. В роботі використано однофракторний дисперсійний аналіз. Результати та їх обговорення. Було обстежено 175 хворих з розсіяним склерозом (123 жінки та 52 чоловіки) в динаміці протягом 5 річного періоду спостереження. Середній вік дебюту розсіяного склерозу у пацієнтів спостерігався у 28,46 $\pm 9,13$ років, вік на час встановлення діагнозу становив 31,77 \pm 9,28 років. Середня тривалість захворювання становила 15,48 \pm 7,69 років на початок спостереження. На момент оцінки пацієнтів в 2013 році показник неспроможності за шкалою Ехрапdеd

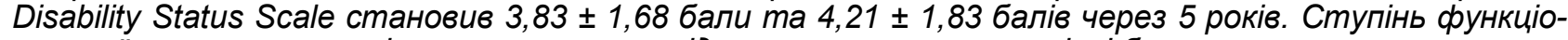
нальної неспроможності за шкалою на вихідному та заключному рівні був статистично значущим $(p=0,02)$. Проведений однофракторний дисперсійний аналіз показав, що найбільшу значимість на ступінь різниці балу за шкалою Expanded Disability Status Scale має показник cmami (p <0,007). Buсновки. Найвпливовішим фрактором, за даними нашого спостереження, на ступінь неспроможності пацієнта в майбутньому є стать. У чоловіків розсіяний склероз настає в молодшому віці, хвороба прогресує швидше, ступінь функціональної неспроможності є вищим порівняно з жінками.

Ключові слова: розсіяний склероз, диспансеризація, демієлінізуючі захворювання, маркери прогресії

Вступ

Перебіг розсіяного склерозу (РC) мінливий та непередбачуваний. Незважаючи на значні зусилля і дослідження протягом десятиліть, досі однією з основних проблем і питань як для неврологів, так і для хворих, залишається визначення прогнозу перебігу РС, фракторів та маркерів прогресії, що впливають на нього.

Можливість визначення ймовірних патернів прогресування РС являє собою ключовий момент у прийнятті рішення про терапію як у нововиявлених хворих, так і при дизайні та інтерпретації клінічних досліджень та планування медичної допомоги [1]. Таким чином, природня історія розвитку PC і прогностичні фрактори є важливою темою для ряду досліджень.

Проспективні дослідження зможуть частково надати оцінку факторів, що визначають прогноз перебігу РС. Ми не знайшли в доступній нам вітчизняній літературі проспективних дослідження РС в популяції українців.

Мета: оцінити фактори що впливають на перебіг розсіяного склерозу (PC) за даними 5річного динамічного спостереження.

\section{Матеріали і методи}

Обласний Центр розсіяного склерозу у Волинській області функціонує 32007 року. В 2012-2013 роках на базі центру була розроблена і введена в практику спеціалізована електро- нна база даних пацієнтів з РС та вперше проведена повна диспансеризація усіх хворих з РС та іншими демієлінізуючими захворюваннями. В реєстр були включені 629 пацієнтів, діагноз яких відповідав критерію №1 McDonald 2010 з поправкою Polman [2]. Iнформовану згоду на детальний огляд 3 використанням спеціалізованих шкал (Expanded Disability Status Test (EDSS) [3], Patient Determent Disease Steps (PDDS)) [4], проведення магнітно-резонансної томографії та динамічне спостереження надали 339 пацієнтів. В 2018 році проведена повторна оцінка пацієнтів 3 проведення клініко-неврологічного обстеження. Інформовану згоду на повторне обстеження надали 175 (51,6\%) пацієнтів. Отримати дані від 119 (35\%) пацієнтів не вдалося у зв'язку зі зміною місця проживання та/або неможливістю телефронного зв'язку. 40 (11,78\%) пацієнтів відмовились від повторного огляду з різних причин. 5 $(1,47 \%)$ хворих померли.

Статистичний аналіз здійснено за допомогою програми Microsoft Excel for Windows, SPSS. B роботі використані стандартні описові статистики. Для аналізу категоріальних використано хіквадрат Пірсона. Статистично значущими вважали результати на рівні $p<0,05$. Для оцінки величини та спрямованості кореляційної залежності використовували коефріцієнт непараметричної кореляції Спірмена. В роботі використано однофракторний аналіз ANOVA. 
Дослідження виконані з дотриманням основних положень «Правил етичних принципів проведення наукових медичних досліджень за участю людини», затверджених Гельсінською декларацією (1964-2013 рр.), ICH GCP (1996р.), Директиви ЄЕС № 609 (від 24.11.1986 р.), наказів МО3 України № 690 від 23.09.2009 р., № 944 від 14.12.2009 р., № 616 від 03.08.2012 p.

\section{Результати дослідження та їх обговорення}

Було обстежено 175 хворих з РС в динаміці протягом 5 річного періоду спостереження. Середній вік дебюту РС у пацієнтів спостерігався у $28,46 \pm 9,13$ років. Середній вік на час встанов- лення діагнозу РС становив $31,77 \pm 9,28$ років. Середня тривалість захворювання становила $15,48 \pm 7,69$ років на початок спостереження. На момент оцінки пацієнтів в 2013 році показник EDSS становив $3,83 \pm 1,68$ бали, середній бал за шкалою PDDS становив 2,78 22,03 балів. Оцінка за шкалою EDSS через 5 років становила $4,21 \pm 1,83$ балів. Всього в дослідження було залучено 123 жінки та 52 чоловіка. Співвідношення жінок до чоловіків склало 2,36:1. Демографрічні характеристики гендерних груп наведені в таблиці 1.

Таблиця 1

Демографрічні дані пацієнтів

\begin{tabular}{|l|c|c|}
\hline & Жінки & Чоловіки \\
\hline Кількість спостережень & 123 & 52 \\
\hline Середній вік, роки & $47,52 \pm 10,04$ & $43,19 \pm 10,28$ \\
\hline Вік на час дебюту, роки & $32,86 \pm 9,04$ & $29,17 \pm 9,41$ \\
\hline Тривалість хвороби, роки & $15,63 \pm 7,63$ & $15,13 \pm 7,8$ \\
\hline
\end{tabular}

Статистично достовірну різницю між жінками та чоловіками на рівні значущості $p<0,005$ встановлено для віку на час дебюту захворювання. В нашій когорті РС у чоловіків спостерігався у більш ранньому віці порівняно з жінками.

Ступінь фуннціональної неспроможності за шкалою EDSS на вихідному та заключному рівні був статистично значущим $(p=0,02) .3$ метою подальшої оцінки фракторів, що впливають на ступінь неспроможності пацієнтів з РС, ми користали показник різниці (дельта) між балом за шкалою EDSS та вихідним балом за даною шкалою при включенні в дослідження. Так, статистично достовірну різницю в балі за шкалою EDSS на рівні $p=0,059$ було виявлено між чоловіками та жінками. Показники різниці за балом EDSS наведені нижче ( рис. 1, рис.2. ).

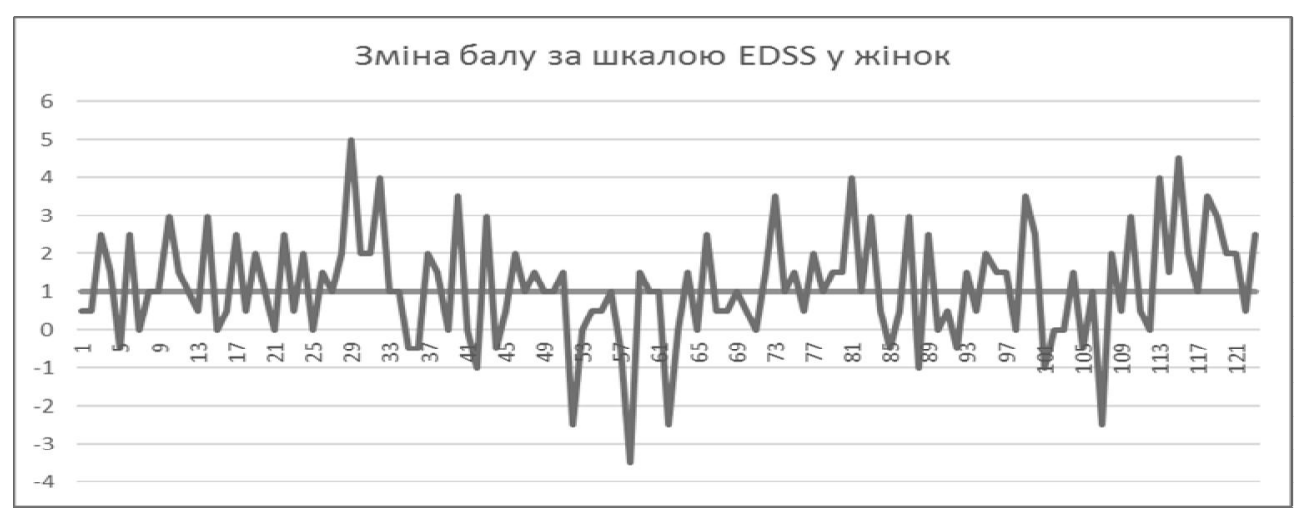

Puc. 1 Зміна балу за шкалою EDSS у жінок

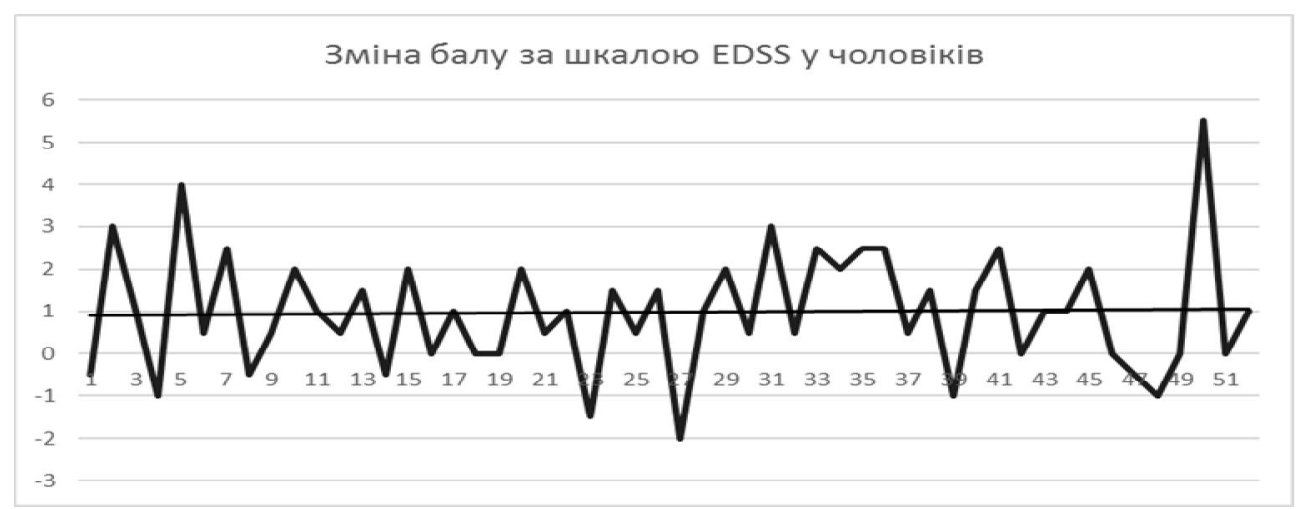

Puc. 2 Зміна балу за шкалою EDSS у чоловіків 
Таблиця 2

Кореляційні зв'язки між показником різниці балу за шкалою EDSS

\begin{tabular}{|l|c|}
\hline & \multicolumn{1}{|c|}{ Коефіцієнт кореляції } \\
\hline Вік пацієнта на час дебюту, роки & 0,73 \\
\hline Вік пацієнта, роки & 0,66 \\
\hline Вихідний бал за шкалою EDSS, бали: & 0,51 \\
\hline Вихідний бал за шкалою PDDS, бали & 0,62 \\
\hline Тривалість хвороби, роки & 0,48 \\
\hline
\end{tabular}

Цікавим нам було оцінити кореляційні зв'язки між показником різниці за шкалою EDSS з іншими показниками (Таб.2).

Отже, сильний кореляційний зв'язок було виявлено з показником віку пацієнта на час дебюту. Решта з представлених показників виявили помірний зв'язок.

Проведений однофракторний аналіз ANOVA показав, що найбільшу значимість на ступінь різниці балу за шкалою EDSS має показник статі $(p<0,007)$.

Результати нашого дослідження частково співпадають з проведеними раніше. Так, за даними Runmaker та ін. (1994), клінічний фрактор, що також міцно пов'язаний з можливим прогнозом перебігу хвороби - вік при дебюті РС. Відомим фактом $€$ той, що більш молодий вік при дебюті пов'язаний з імовірністю більш повільного прогресування хвороби, i, відповідно, кращим прогнозом. Але, як повідомляє Runmarker В., цей ризик може досягнути свого максимального рівня, який у декілька разів вищий вже приблизно через 15 років. Пацієнти з пізнішим дебютом мають значно вищий ризик досягнути високої інвалідизації з результатом 6 за шкалою EDSS одразу після початку захворювання, але досягають максимуму вже через декілька років, після чого цей ризик знижується [5].

Згаданий фракт підтверджується 3-ма багатопараметровими аналізами даних усіх типів перебігу РС (дослідження реєстру Ветеранів США, Онтаріо та Британської Колумбії), згідно з якими пізній вік початку хвороби є несприятливим прогностичним фоктором, а клінічний перебіг, найімовірніше, буде прогресуючим і його прояви стрімкими [6, 7]. Дослідження, проведені в клініці Ліону, продемонстрували не тільки цікавий віковий зв'язок, але й гендерний вплив. Це й же ж фактор виявився вагомим і в нашій когорті пацієнтів. Так, за результатами дослідження Confavreux C. и Vukusic S. було визначено, що жінки досягають меж інвалідності в більш старшому віці, ніж чоловіки. Також чоловіча стать і ранній дебют РС, але не первинна симптоматика, були пов'язані з більш раннім віком інвалідизації (досягнення раніше згаданих рубежів за шкалою EDSS) [8]. Відповідно можна сказати,

\section{Реферат}

ПРОГНОЗ ТЕЧЕНИЯ РАССЕЯННОГО СКЛЕРОЗА: РЕЗУЛЬТАТЫ ПРОСПЕКТИВНОГО ИССЛЕДОВАНИЯ Шульга О. Д.

Ключевые слова: рассеянный склероз, диспансеризация, демиелинизирующие заболевания, маркеры прогрессии

Актуальность: Течение рассеянного склероза изменчиво и непредсказуемо. Несмотря на значительные усилия и исследования в течение десятилетий, до сих пор одной из основных проблем и вопросов как для неврологов, так и для больных, остается определение прогноза течения рассеянного що чоловіча стать також $є$ несприятливим прогностичним фактором, що впливає на перебіг PC. На думку Niscot et al., кращий прогноз серед жінок пояснюється наявністю гормональних змін і впливом статевих хромосомів на імунну систему, гематоенцефалічний бар'єр, паренхиматозні клітини ЦНС. У своєму дослідженні він також посилався на усім відоме поліпшення стану пацієнток після пізньої вагітності, що також можна пов'язати з гормональними змінами [9].

Отже, розсіяний склероз має досить гетерогенний перебіг і різні клінічні прояви. Ця хвороба непроста в діагностиці, однак ще складніше визначити прогноз її перебігу. Можливість прогнозувати перебіг і прогресію РС - ключове питання для надання медичної допомоги хворим з РC, особливо з урахуванням важливості початку

Висновки: Найвпливовішим фактором, за даними нашого спостереження, на ступінь неспроможності пацієнта в майбутньому є стать. У чоловіків РС настає в молодшому віці, хвороба прогресує швидше, ступінь функціональної неспроможності $є$ вищим порівняно з жінками.

\section{Література}

1. Rojas JI, Tizio S, Patrucco L, Cristiano E. Oligoclonal bands in multiple sclerosis patients: worse prognosis? Neurological Research. 2012 2 No 2000088.
10.1179/1743132812y.0000008.

2. Polman $\mathrm{CH}$, Reingold SC, Banwell $\mathrm{B}$ et al. Diagnostic criteria for multiple sclerosis: 2010 revisions to the McDonald criteria. Ann Neurol. 2011;69(2):292-302.

3. Kurtzke JF. Rating Neurologic Impairment in Multiple Sclerosis an Expanded Disability Status Scale (EDSS). Neurology. 1983;33:1444-4.

4. Shulga OD. Validation of the Ukrainian Version of Patient Determined Disease Steps in Multiple Sclerosis. International neurological journal. 2016;3.81:167-172.

5. Runmarker, B, Andersson, C, Odén, A. et al. Prediction of outcome in multiple sclerosis based on multivariate models. $J$ Neurol. 1994; 241: 597-604. https://doi.org/10.1007/BF00920623

6. Degenhardt, A, Ramagopalan, SV, Scalfari, A, Ebers, GC. Clinical prognostic factors in multiple sclerosis: a natural history review. Nature Reviews. Neurology. 2009; 5(12): 672-82.

7. Kis $B$, Rumberg B, Berlit P. Clinical characteristics of patients with late-onset multiple sclerosis. Journal of Neurology. 2008 May;255(5):697-702. DOI: 10.1007/s00415-008-0778-x.

8. Kis, B, Rumberg, B, Berlit, P. Clinical characteristics of patients with late-onset multiple sclerosis. J Neurol . 2008; 255, 697-702. https://doi.org/10.1007/s00415-008-0778-x

9. Nicot A. Gender and sex hormones in multiple sclerosis pathology and therapy. Frontiers in bioscience (Landmark edition). 2009; 14 , 4477-4515. doi:10.2741/3543 ранньої терапії. 
склероза, факторов и маркеров прогрессии, влияющие на него. Проспективные исследования смогут частично дать оценку факторов, определяющих прогноз течения рассеянного склероза.

Цель: оценить факторы, влияющие на течение рассеянного склероза по данным 5-летнего динамического наблюдения.

Материалы и методы: Было обследовано 175 больных с рассеянным склерозом в динамике в течение 5 летнего периода наблюдения. Применяли клинические и паралинические методы обследования. Статистический анализ осуществлен с помощью программы Microsoft Excel for Windows и SPSS. В работе использованы стандартные описательные статистики. Для анализа категориальных использовано хи-квадрат Пирсона. Оценка величины и направленности корреляционной зависимости проводилась с помощью коэффициента непараметрической корреляции Спирмена. В работе использовано однофакторный дисперсионный анализ.

Результаты: Было обследовано 175 больных с рассеянным склерозом (123 женщины и 52 мужчины) в динамике в течение 5-летнего периода наблюдения. Средний возраст дебюта заболевания у пациентов составил 28,46 $\pm 9,13$ лет, возраст на момент установления диагноза рассеянный склероз составил 31,77 \pm 9,28 года. Средняя продолжительность заболевания составляла 15,48 \pm 7,69 лет до начала наблюдения. На момент оценки пациентов в 2013 году показатель Expanded Disability Status Scale составлял 3,83 \pm 1,68 балла и 4,21 \pm 1,83 баллов через 5 лет. Степень фрункциональной несостоятельности по шкале Expanded Disability Status Scale на исходном и заключительном уровне был статистически значимым ( $p=0,02)$. Проведенный однофакторный дисперсионный анализ показал, что наибольшую значимость на степень разницы балла по шкале Expanded Disability Status Scale имеет показатель пола ( $\mathrm{p}<0,007)$.

Выводы: ведущим фактором, по данным нашего наблюдения, на степень несостоятельности пациента в будущем является пол. У мужчин рассеянный склероз наступает в более молодом возрасте, болезнь прогрессирует быстрее, степень функциональной несостоятельности выше по сравнению с женщинами.

\begin{abstract}
Summary
PREDICTION OF MULTIPLE SCLEROSIS COURSE: RESULTS OF PROSPECTIVE STUDY

Shulga O.D.

Key words: course of the disease, prognosis, disability, Expanded Disability Status Scale, scoring, sex.

Background: The course of multiple sclerosis is variable and unpredictable. Despite considerable efforts and research over the decades, one of the major challenges for both neurologists and patients is still to determine the prognosis of multiple sclerosis as well as the factors and markers affecting its progression. Prospective studies can partially contribute to assessment of the factors predetermining the prognosis of the course of multiple sclerosis.
\end{abstract}

Objective: To evaluate the factors affecting the course of multiple sclerosis according to a 5-year prospective dynamic observation.

Materials and methods: 175 patients with multiple sclerosis were examined over a 5-year follow-up period. The methodology employed was as follows: statistical analysis by using Microsoft Excel for Windows and SPSS; standard descriptive statistics; calculation of Pearson's chi-square for categorical analysis; single-factor analysis of variance. The magnitude and directivity of the correlation dependence were estimated using the Spearman non-parametric correlation coefficient.

Results: 175 patients with multiple sclerosis (123 women and 52 men) were examined over a 5-year follow-up period. Mean age of patients at the onset of multiple sclerosis was $28.46 \pm 9.13$ years; mean age at the time of diagnosis of the disease was $31.77 \pm 9.28$ years; the mean length of the disease was $15.48 \pm$ 7.69 years prior the start of the observation. At the time of the patients' status assessment in 2013, the Expanded Disability Status Scale value was $3.83 \pm 1.68$ scores and $4.21 \pm 1.83$ scores in 5 years. The degree of functional disability according to the Expanded Disability Status Scale baseline was statistically significant $(p=0.02)$. A single-factor analysis of variance showed that sex $(p<0.007)$ was of the highest significance for the degree of difference by the Expanded Disability Status Scale.

Conclusions: According to results obtained, we can suggest the most influential factor for a patient's disability due to multiple sclerosis is sex. Men may develop multiple sclerosis at younger age, the disease in men progresses faster, thus, the degree of functional disability is higher compared with women. 